\title{
Índice de Controle de Capitais: Uma Análise da Legislação e seu Impacto Sobre o Fluxo de Capital no Brasil no Período 1990-2000`
}

\author{
- Maria Cristina Terra* - Elena Solhet**
}

\begin{abstract}
RESUMO
Cardoso e Goldfajn (1997) constroem um índice de controle de capital para o Brasil para o período de 1988 a 1995, e estudam o efeito do índice sobre o fluxo de capitais. Este trabalho se propõe a construir o índice apresentado naquele trabalho para o período de 1990 a 2000, e estudar, em termos quantitativos, a influência deste índice sobre os fluxos de capitais. Foram analisados cerca de 200 principais normativos editados pelo Banco Central e Ministério da Fazenda, referentes a controle de capital no período 1990-2000. O período foi marcado pela liberalização do fluxo de capital, com alguns subperíodos nos quais houve restrição principalmente à saída de capital. Os resultados empíricos mostram que o índice de controle de capital, bem como desvios da paridade coberta de juros, o Plano Real e os efeitos provocados pelas crises mexicana, asiática e russa foram fatores determinantes para explicar o fluxo de capital total entre 1990 e 2000.
\end{abstract}

\section{Palavras-chave}

controle de capital, fluxos de capital

\section{ABSTRACT}

Cardoso and Goldfajn (1997) build an index of capital control for Brazil for the period 1988 to 1995, and they study the impact of the index on the capital flows. This paper computes the same index for the period 1990-2000 and analyzes, quantitavely, the impact of this index on capital flows. The period studied was characterized by the liberalization of capital flows, with a few sub-periods where restriction were imposed, specially to capital outflows. The empirical results show that the capital control index helps explaining the total capital flows between 1990 and 2000, together with deviation from covered interest parity, the Real Stabilization Plan, and the impact of the Mexican, Asian and Russian crises.

\section{KEY WORDS}

capital control, capital flows

\section{JEL ClassificATION}

$F 39, G 15, G 18$

\footnotetext{
- As autoras agradecem as sugestões e comentários do Prof. Fernando Blumenschein (FGV) que tanto ajudaram no aperfeiçoamento do trabalho. Maria Cristina Terra agradece o auxílio financeiro do CNPq e do PRONEX, e Elena Sohiet é grata ao apoio da CAPES.

* Escola de Pós-Graduação em Economia/Fundação Getulio Vargas. E-mail: terra@fgv.br. End. para contato: EPGE-Fundação Getulio Vargas - Praia de Botafogo, 190 sala II08 Rio de Janeiro, RJ, 22.250-900. Tel. (552I) 2559-5844 - Fax. (552I) 2553-882I.

** Universidade Federal Rural do Rio de Janeiro/Instituto Multidisciplinar. E-mail: e.soihet@globo.com. (Recebido em abril de 2005. Aceito para publicação em maio de 2006).
} 


\section{INTRODUÇÃO}

Na década de 1990 ocorreram importantes transformações no mundo que apontavam para um período de economias mais abertas. O ressurgimento do fluxo de capital, a partir de 1990 foi, em parte, reflexo da maior integração financeira e de um vasto processo de desregulamentação ocorrido tanto nos países desenvolvidos como nos países em desenvolvimento. A queda dos custos de comunicação e a rapidez de acesso à informação levaram os países industriais a buscar rendimentos também nos países em desenvolvimento.

A elevação do fluxo de capitais e a ocorrência de crises financeiras em escala mundial despertaram o interesse para várias investigações teórico-empíricas sobre o tema do fluxo de capitais. A maioria dos trabalhos está centrada em dois focos principais. O primeiro foco está relacionado com a influência dos fluxos na performance macroeconômica dos países em desenvolvimento e a eficácia, ou não, de se controlar a entrada do capital externo. A entrada de capitais impóe uma série de problemas de política macroeconômica, como apreciação de moeda e vulnerabilidade no balanço de pagamentos.

O segundo foco se relaciona com a identificação dos fatores que determinam esse fluxo, isto é, se os capitais são mais atraídos pelos fatores internos - efeito pull - ou pelos fatores externos - efeito push. O efeito pull diz respeito às condições domésticas; são fatores que atraem os recursos estrangeiros como resultado da melhoria de risco dos países. Os principais fatores pull, apontados pela literatura, são os diversos aspectos institucionais de cada país, a taxa de juros interna, o nível de atividade e a taxa de investimento. $\mathrm{O}$ efeito push refere-se às condições desfavoráveis nos países desenvolvidos, tais como a deterioração da relação entre risco e retorno dos ativos nos países desenvolvidos. ${ }^{l}$

O presente trabalho se propõe a contribuir para o debate em torno de fluxo de capitais no Brasil. Nossa contribuição será construir o Índice de Controle de Capital (ICC) para o período de janeiro 1990 a dezembro 2000, usando a metodologia de Cardoso e Goldfajn (1997). Para sua construção realizou-se um minucioso trabalho de pesquisa que abordou cerca de duzentos principais normativos editados pelo Banco Central e Ministério da Fazenda que afetaram a entrada e saída de capital estrangeiro no período de 1990 a 2000. A outra contribuição será analisar os determinantes do fluxo de capital no Brasil para o período citado, enfatizando o papel da legislação sobre controle de capital, por meio do índice construído. O período foi escolhido por

1 Segundo Calvo et alii (1993) e Fernándes-Arias (1996), na maioria dos países emergentes o efeito push prevalece sobre o efeito pull. Isso explica em parte a volatilidade do fluxo de capital, já que os fatores push não estão sujeitos ao controle das autoridades econômicas. 
ser uma década rica para análise econômica, marcada por importantes acontecimentos tanto externos - três crises financeiras internacionais (mexicana, asiática e russa) - e internos, como o Plano Real e as mudanças de regime cambial.

O trabalho apresenta a seguinte estrutura. A seção 1 apresenta uma revisão da literatura acerca do debate sobre a adoção dos controles de capitais. Na seção 2 foram analisados o comportamento e a composição do fluxo de capital, no período 19902000, à luz das mudanças na legislação, com objetivo de ressaltar os principais fatos estilizados. A seção 3 foi dedicada à construção dos índices de controle de capital, à investigação econométrica dos determinantes de fluxos de capital, seus aspectos metodológicos e análise dos resultados. Na última seção estão as principais conclusões do trabalho.

\section{CONTROLE DE CAPITAIS}

\subsection{Breve Histórico}

Os controles de capitais englobam os instrumentos de intervenção no livre movimento de capitais e prevaleceram durante grande parte do século XX. Ao limitar a saída de capital, o controle foi usado para financiar as duas grandes Guerras Mundiais. (FMI, v. 2 n, 4, 2001). Nos anos 1970, as economias desenvolvidas começaram um movimento de liberalização do controle de capital cuja tendência foi acompanhada pelas economias em desenvolvimento a partir dos anos 1990. O uso de controle tem sido objeto de intenso debate tanto nos círculos acadêmicos como na política econômica. Se de um lado muitos países foram beneficiados pela grande entrada de capital via investimentos, por outro, exacerbou os riscos associados a essas economias ao expô-las a crises financeiras provocadas por repentinos reversos no fluxo de capital.

Na prática, há diversos tipos de controles de capitais impostos pelos países, desde o controle extensivo (cobrindo a totalidade das operações financeiras, como foi o caso da China) até os casos mais brandos relacionados a um controle seletivo e temporário. Os controles seletivos são aqueles que cobrem alguma modalidade de operação financeira, enquanto o controle temporário ocorre apenas durante um período de tempo e geralmente está associado a um processo gradual de liberalização financeira, até que as condições ideais para integração financeira de um país com o resto do mundo estejam estabelecidas. Há ainda o controle de entrada de capitais externos, que apenas incide sobre o fluxo de entrada e se justifica como uma função preventiva durante os períodos de boom. Esse controle é considerado uma política de prudência, especialmente em países de renda baixa, sem um sistema financeiro sofisticado. Já o 
controle de saída de capitais é o mais controverso e tem dois efeitos: por um lado estancam as saídas de capital, em um momento de crise aguda até que as autoridades tomem uma ação corretiva, mas, por outro lado, podem tirar a confiança do mercado e atrasar os ajustes necessários, como enfatizado nos modelos de ataques especulativos de segunda geração. Uma restrição financeira pode levar os investidores a perceberem que essas restrições serão futuramente uma ameaça à remessa de seus retornos ao exterior, havendo, portanto, uma redução no fluxo de capital.

\subsection{Os Efeitos do Controle de Capital}

A literatura favorável à livre e total movimentação de capitais argumenta que a mobilidade de capitais aumenta o bem-estar do consumidor. O movimento de capitais direciona a poupança para onde o capital é mais produtivo, favorecendo o investimento e crescimento econômico. Além disso, é possível a diversificação do portfolio dos investidores, o partilhamento de risco entre as economia e trocas intertemporais, permitindo a suavização do consumo dos agentes econômicos.

Por outro lado, o aumento da volatilidade é um dos argumentos centrais para aqueles que se opóem à completa liberalização do movimento de capitais. A excessiva mobilidade de capitais pode levar à apreciação cambial devido às grandes entradas de fluxo de capitais em períodos de alta liquidez no mercado internacional de crédito e, conseqüentemente, a uma elevação da fragilidade externa. Assim, o objetivo do controle de capital é criar mecanismos que reduzam o impacto do fluxo por meio da intervenção direta da autoridade monetária via uma política de imposição de controle de capitais.

De acordo com alguns autores, como Williamson e Eichengreen, o controle de capital pode fazer mais mal do que bem, se são tratados como panacéia que substitui políticas adequadas. ${ }^{2}$ De acordo com Lessar e Williamson (1987), a fim de evitar uma fuga de capitais $^{3}$ é preciso restaurar a confiança por meio de políticas macroeconômicas sustentáveis, como, por exemplo, taxa de câmbio realista, taxa real de juros positiva, porém moderada, crescimento econômico robusto e uma resolução de médio prazo para o problema da dívida. Além dos chamados fundamentos macroeconômicos, Lessar e Williamson (1987) reforçam que em muitos países não basta uma mudança na política macroeconômica, é necessário uma mudança na ética daqueles que estão envolvidos na vida pública. De acordo com o artigo, uma sociedade com líderes corruptos pode

2 Lessar e Williamson (1987) Eichengreen et al. (1998, 1999).

3 Williamson faz uma distinção detalhada entre a saída e a fuga de capitais. Resumidamente, a saída de capital seria algo normal, relacionado ao investidor que sai de um país em busca de maiores retornos, enquanto a fuga reflete uma saída extraordinária impulsionada por uma complexa lista de medos e suspeitas percebidas por alguns ou todos os agentes econômicos. 
ser condenada por repetidos ataques de fuga de capital. Eichengreen (2003) aponta como fontes de vulnerabilidade a governança corporativa mal desenvolvida, a infraestrutura débil e disciplina de mercado, a supervisão e regulação inadequadas - o que na literatura seria referido como instituições fracas e políticas estruturais defeituosas. Ele adverte para o fato de que se deve evitar o chamado "Capitalismo de compadres", em que os negócios econômicos e financeiros sejam organizados com base em laços de família e conexões políticas. Para outros autores, como Joseph Stiglitz (2002), deve haver políticas que desencorajem o capital de curto prazo, o chamado hot money, em prol do fluxo de longo prazo. O excesso de mobilidade de capital é parcialmente responsável pelas crises financeiras e instabilidade macroeconômica. Assim, a remoção do controle de capital necessita ser coordenada com outras políticas, devendo levar em conta a estabilidade macroeconômica do país e o desenvolvimento do sistema financeiro sob o risco de aumentar a vulnerabilidade externa.

Mesmo a literatura favorável à livre e total mobilidade de capitais reconheceu que a interrupção súbita dos financiamentos leva a ajustes ineficientes, deteriorando os efeitos positivos sobre o crescimento. Neste sentido, as crises sistêmicas da década de 1990, principalmente a partir da asiática em 1997, levaram a uma reflexão e debate sobre os movimentos demasiadamente rápidos e prematuros de liberalização da conta capital. Ainda em 1998, em entrevista ao Financial Times (fevereiro, 1998), o diretor do FMI, Michel Candessus, afirmou que a política econômica deve incentivar a liberalização do fluxo de capital, mas com sensatez e uma certa ordem, argumentando que a última coisa a ser liberada é o movimento do capital de curto prazo. Anne Krueger, vice-gerente geral do FMI, admitiu a necessidade de se criar um mecanismo para lidar com as crises financeiras. Seu discurso em 2001 marcou a primeira vez que o FMI reconheceu a necessidade de uma reforma fundamental na maneira de administrar as crises financeiras. De acordo com Calvo (1996), quando há uma interrupção repentina dos fluxos - sudden stops -, países emergentes levam mais desvantagens em relação aos desenvolvidos porque perdem acesso ao mercado internacional de capitais. O sudden stop normalmente leva à contração do produto, altera preços relativos e provoca a depreciação da moeda doméstica. Ele pode ser ainda mais prejudicial quando resulta em falência bancária.

Como lidar com o fenômeno do sudden stop? As evidências empíricas em relação à interrupção brusca do fluxo de capitais e à utilização do controle de capitais são polêmicas. $\mathrm{O}$ controle pode ser útil para lidar com capital volátil ao dar à economia a possibilidade de um alívio até que sejam implementadas as reformas econômicas. (Ariyoshi et al., 2000). Contudo, o controle pode também causar distorções. Em países com impedimentos legais de mobilidade de capital, o setor privado em geral encontra meios de driblar o controle legal no fluxo de capital. De acordo com Sebastian Edwards (1998), o grande volume de fuga de capital ocorrida na América Latina na 
crise da dívida de 1982 claramente mostrou como o setor privado pode ser extremamente criativo para encontrar meios de se escapar ao controle legal.

O Chile e a Colômbia foram os principais países na América Latina que utilizaram controle de capital na década de 1990. Em ambos os países esse controle teve como objetivo evitar a apreciação real da taxa de câmbio, especialmente quando surgia um elevado fluxo de entrada de capital. No Chile, o controle foi introduzido em 1991, enquanto na Colômbia ocorreu em 1993. Tanto no Chile quanto na Colômbia as restrições ao movimento de capitais agiram como um imposto implícito ao financiamento estrangeiro. $\mathrm{O}$ caso chileno, por ser associado geralmente a uma experiência bem-sucedida, mereceu considerável atenção por parte dos analistas. Principalmente após a crise asiática, o controle de capital tomou duas formas básicas: estadia mínima obrigatória dos fluxos de investimento direto e depósito não remunerado no Banco Central para outros fluxos. Pesquisa realizada por Valdez-Prieto e Soto (1996) mostrou que os controles chilenos alteraram a composição das entradas de capital: desencorajaram o fluxo de curto prazo e ajudaram a alongar a maturidade média desses fluxos. Edwards (1998) confirmou essa conclusão e mostrou que entre 1988 e 1997 houve um aumento do fluxo total de capital, apesar dos controles de entrada, à exceção de um breve declínio em 1993.

No caso da Ásia, um texto relevante na literatura é o de Kaplan e Rodrik (2001). Os autores compararam a recuperação da Malásia, após a adoção do controle de capitais em setembro de 1998, com a experiência da Coréia e Tailândia, que seguiram as políticas ortodoxas recorrendo ao FMI. Eles encontraram em seus resultados que a Malásia obteve uma recuperação mais rápida em sua produção, menores declínios no emprego e no salário real, além de uma reação mais rápida no mercado financeiro. Ainda relatam que no caso da Malásia não houve nenhuma indicação de aumento de corrupção por conta do controle, uma vez que as medidas tomadas foram transparentes e eficientes.

Recentemente, Edwards (2005) não encontrou evidência empírica sugerindo que países com mais mobilidade de capital são mais propensos a crises. Na mesma linha, Goldfajn e Minella (2005), ao detalharem a experiência do Brasil com a mobilidade e o controle de capitais, mostraram que progressos foram conseguidos na redução da vulnerabilidade externa a partir da década de 1990 até 2005 com a liberalização da conta capital. O setor privado reduziu significativamente sua participação na dívida externa e o investimento estrangeiro direto tornou-se a fonte mais importante de financiamento substituindo o investimento em portfolio.

Assim, como vimos, os efeitos macroeconômicos do controle de capital permanecem sujeitos a intensa pesquisa empírica com resultados diversos. 


\section{COMPORTAMENTO DO FLUXO DE CAPITAIS}

\subsection{Fluxo Total}

A liberalização da conta capital no Brasil começou no final dos anos 1980, mas foi nos anos 1990 que houve a consolidação definitiva de seu processo de abertura. Pode-se destacar quatro fatos relevantes para o aumento do fluxo de capital nesse período.

O primeiro fato foi a normalização das relações do País com a comunidade financeira internacional, por meio da regularização da renegociação da dívida externa com os bancos credores e da conclusão, em abril de 1994, da regularização dos empréstimos atrasados nos moldes do Plano Brady. O segundo fato a destacar foi o advento do Plano Real em julho de 1994, que consolidou a estabilidade macroeconômica ao País. O terceiro fato diz respeito ao aparato regulatório que proporcionou uma legislação liberalizante dos fluxos de capitais entre 1990 e 2000. Por fim, o quarto fato está relacionado a fatores externos, tal como a queda da taxa de juros internacional nos países desenvolvidos, que levou os investidores a procurar oportunidades mais atrativas em países em desenvolvimento, como o Brasil. De acordo com dados do Banco Central, ${ }^{4}$ o fluxo de capitais em 1990 era de US\$ 4,26 bilhões (0,9\% do PIB), e passou ao final de 2000 para US\$22,3 bilhões (cerca de 3,8\% do PIB). Entre 1990 e 2000, os investimentos diretos estrangeiros foram responsáveis por entradas líquidas de US\$ 123,9 bilhões, enquanto os investimentos em portfólio significaram entradas de US\$ 32,2 bilhões, correspondendo a apenas $26 \%$ dos investimentos diretos. Antes do Plano Real, os fatores macroeconômicos internos não pareciam suficientemente consolidados para atrair capital estrangeiro. A partir de 1995, os fluxos líquidos de investimentos estrangeiros evidenciaram uma alteração importante. A participação dos investimentos diretos, que em 1994 representava 21\% do total das inversões estrangeiras, aumentou para 65\% em 1995.

Em 1997 e 1998 constatou-se que apesar das crises internacionais, asiática e russa, os investimentos diretos continuaram a subir em relação aos anos anteriores. Isto pode evidenciar que, naquele período, os investimentos estavam mais atrelados a fatores internos relacionados à estabilidade das variáveis macroeconômicas do País (efeito pull) do que aos efeitos externos (push e contágio). Quanto às privatizações, estas tiveram uma participação, no período 1996 a 2000, de 24\% dos ingressos de investimentos diretos. O auge dos investimentos em privatizaçôes e concessôes públicas ocorreu no período 1997-1999, quando estes somaram US\$20,2 bilhões, com destaque para os ingressos relativos aos setores de mineração, ferroviário e telecomunicação. É im-

4 Estes dados foram consolidados a partir das notas para imprensa disponíveis no site www.bcb.gov.br 
portante destacar que, apesar de expressivos, os investimentos em privatização representam apenas a quarta parte, aproximadamente, do total de ingressos, o que revela a autonomia dos investimentos diretos relativamente ao processo de desestatização. (Relatório do Banco Central, 1998).

\section{GRÁFICO I - MOVIMENTO DE CAPITAIS - PRINCIPAIS COMPONENTES}

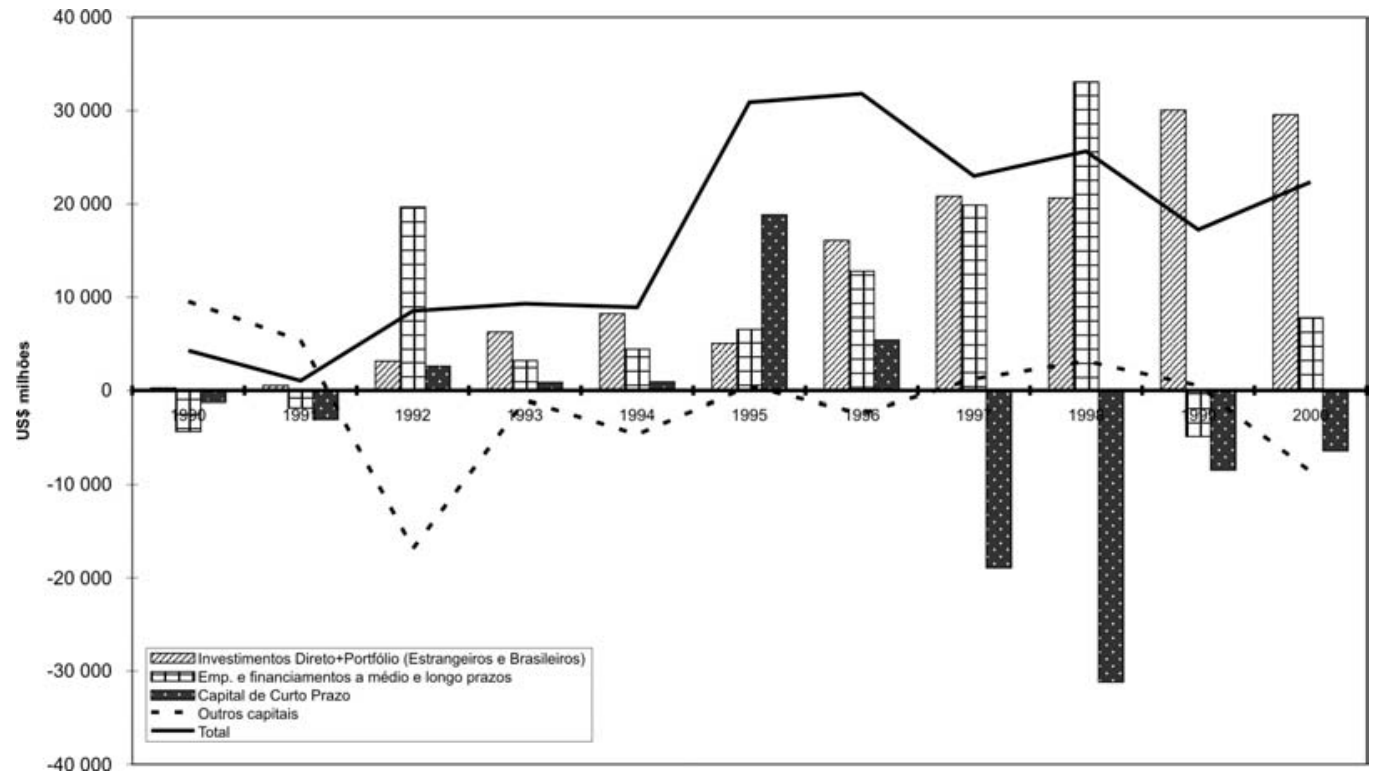

Fonte: Dados Primários do Banco Central do Brasil

O investimento em portfólio, embora tenha participação menor que o investimento direto, envolve uma grande massa de recursos. No período 1990-2000, o saldo de investimento de portfólio foi de US\$ 32,2 bilhões, correspondendo a uma entrada de US\$ 38,4 bilhões relativos aos Anexos I a V, ${ }^{5}$ enquanto os fundos de renda fixa, privatização, imobiliário e de empresas emergentes representaram uma saída de US\$ 6,2 bilhões. Tais fundos só tiveram papel relevante em 1994, quando entraram US\$ 2,3 bilhões; nos demais anos, houve pouco fluxo por meio desse instrumento.

\subsection{Financiamentos e Empréstimos de Médio e Longo Prazos}

Por meio dos financiamentos estrangeiros houve entradas líquidas no período 1990 2000 de cerca de US\$ 8,7 bilhões. As entradas líquidas ocorreram em apenas três anos do período (1992, 1997 e 1998). No ano de 1992, a conta financiamentos foi

5 Anexo I - Sociedade de investimento; Anexo II - Fundo de investimento; Anexo III e IV - Carteira de títulos e valores mobiliários; Anexo V - Depositary Receipts (Relatório Econômico "Brasil para Investidores Estrangeiros") (ANDIMA, 1999). 
alta devido à elevada entrada de refinanciamentos (US\$ 11,6 bilhões) ${ }^{6}$ explicada pela regularização dos empréstimos atrasados, amparados pelo acordo assinado com o Clube de Paris. ${ }^{7}$ A melhora no fluxo de capital total tornou possível ao País amortizar seus financiamentos e, portanto, essa conta ficou negativa entre 1993 e 1996. A reversão ocorreu em 1997, quando os créditos de fornecedores-compradores ${ }^{8}$ passaram de um valor negativo de US\$ 1,1 bilhão em 1996 para um valor positivo de US\$ 12,6 bilhões, devido a mudanças na legislação. ${ }^{9}$ Tendo em vista a alta taxa de juros no Brasil, os importadores preferiam adiar o pagamento de seus créditos de curto prazo, passando a captar recursos no médio e longo prazos. A partir de 1999, com a liberalização da legislação para créditos à importação de curto prazo, os importadores amortizaram suas dívidas no médio e longo prazos e, com isso, a conta de fornecedores-compradores sofreu uma queda.

Já os empréstimos de médio e longo prazo foram responsáveis pela entrada líquida de US\$ 95,8 bilhões no período 1990-2000. Desse total, as notes participaram com 71\% dos empréstimos (US\$ 66 bilhões), com destaque para os anos de 1996 e 1998. Em segundo lugar, em termos de participação, mas bem abaixo das notes, vêm os empréstimos intercompanhias (17,1\%), seguidos de bônus $(5,9 \%)$ e commercial paper $(4,3 \%)$. As outras formas de empréstimos, como bancos, securitização e refinanciamentos, não foram significativas no período.

\subsection{Capital de Curto Prazo}

Os capitais de curto prazo são operações com prazo inferior a 360 dias. Em geral, esses fluxos apresentam maior volatilidade, por terem prazos menores que outras formas de investimento. Esse tipo de operação ficou positivo a partir de 1992, tendo seu auge em 1995, quando atingiu o valor de US\$ 18,8 bilhões. Observa-se, ainda, que há forte influência da instabilidade do mercado financeiro internacional sobre o fluxo de capital no Brasil. A crise do México, por ser a primeira, alertou os agentes financeiros sobre a possibilidade do "efeito contágio". No entanto, não chegou a afetar o capital de curto prazo. Provavelmente, tal fato está relacionado à implementação do Plano Real. Nesse caso, o efeito pull pode ter superado os efeitos negativos dos choques externos (efeito contágio).

6 Ver Relatório do Banco Central - 1992.

7 Reunião dos credores para discutir os problemas dos países endividados.

8 São créditos concedidos a importadores/exportadores no exterior a residentes no Brasil para a importação de bens.

9 O ganho com arbitragem beneficiou os importadores, mas piorou a balança comercial. Para aliviar o problema, as autoridades monetárias obrigaram os importadores a pagar suas mercadorias em um prazo até 180 dias antes de a mercadoria chegar ao Brasil. O reflexo dessa medida foi o aumento na conta de fornecedores/compradores cujos prazos de financiamento eram maiores que 360 dias. Dados de 1998 mostram que essa conta permaneceu alta (US\$6,3 bilhóes), porém menor que em 1997, ainda influenciada pelo impacto da conta de fornecedores e compradores. 
A partir de 1996, há uma reversão dos capitais de curto prazo. Nesse ano, as autoridades monetárias estavam com a intenção de melhorar a qualidade do fluxo de capital no País, diminuindo as entradas de curto prazo e aumentando as de longo prazo. Contudo, as saídas do fluxo de capital foram muito mais expressivas a partir da crise asiática em 1997 e da crise russa em 1998. A partir do segundo semestre de 1997 houve um esforço, por parte das autoridades monetárias, de melhorar a captação de recursos. O Banco Central liberalizou, então, o prazo mínimo para a contratação, renovação e prorrogação de operações de empréstimos externos. (Circular $\mathrm{n}^{\circ} 2.783$, de 13.11.1997, e Circular no 2834, de 24.06.1998). No entanto, esse esforço não foi suficiente para a entrada de recursos externos. Isto só veio a acontecer após o acordo com o FMI, em fins de 1998, e após a adoção câmbio flutuante, em início de 1999. Em 1999 e 2000, o fluxo de capital de curto prazo continuou negativo, porém já se notou uma clara reversão dessa tendência. As saídas do capital de curto prazo diminuíram de US\$ 31 bilhões, em 1998, para US\$ 8,8 bilhões e US\$ 6,4 bilhões, respectivamente, em 1999 e 2000 . A entrada de US\$ 9 bilhóes, após o acordo como o FMI, refletiu a volta da confiança dos investidores estrangeiros em relação ao Brasil, resultando em saídas cada vez menores dos capitais de curto prazo.

\section{3. ÍNDICE DE CONTROLE DE CAPITAL}

\subsection{Metodologia}

A coleta da legislação sobre fluxo de capitais, para o período entre janeiro 1990 e dezembro de 2000, foi realizada com base nas normas editadas pelo Departamento de Capitais Estrangeiros (FIRCE) do Banco Central do Brasil. Além disso, foram realizadas entrevistas com técnicos do Departamento Econômico do Banco Central, em Brasília, para complementar nosso trabalho. Além de cobrir a legislação do FIRCE, também selecionamos as normas relacionadas, isto é, aquelas que revogam, alteram, ou aprimoram a legislação e que não eram abrangidas pelo FIRCE. Assim, conseguimos reunir um universo de 189 normativos nesse período.

A legislação foi classificada conforme o tipo de normativo (Resolução, Circular, CartaCircular, Comunicado e Portaria), foi definido o caráter das normas (liberalizante, restritiva ou regulamentar) e classificada por item ou conta de balanço de pagamentos (Investimento Direto, Portfólio, Empréstimos, Financiamentos, Curto Prazo). De acordo com o critério adotado, uma norma considerada liberalizante é aquela que tem a intenção de incentivar a movimentação de capitais, como, por exemplo, dar liberdade para remessa de capitais e autorizar a aplicação dos investidores nacionais em títulos emitidos no exterior (DRs). Uma norma restritiva, ao contrário, é aquela que 
desestimula a entrada e saída de capital estrangeiro. Um exemplo de norma restritiva seria o Banco Central limitar o capital estrangeiro a investir em determinados fundos de investimento, ou, ainda, quando há um aumento do IOF sobre fundos de renda fixa. Já uma legislação de caráter regulamentar é aquela que tem apenas a intenção de normatizar ou comunicar um fato, e por isso tem, a princípio, um efeito neutro sobre o fluxo de capital. Normas neutras seriam, por exemplo, aquelas em que o Banco Central disciplina o arrendamento mercantil ou estabelece condições para registro de capitais estrangeiros. De acordo com nossa classificação, no universo de 189 normativos $54,8 \%$ são liberalizantes, $22,1 \%$ são restritivos e $23,1 \%$ são regulamentares.

\subsection{Cálculo do Índice de Cardoso e Goldfajn}

Cardoso e Goldfajn (1997), C\&G, investigam, empiricamente, os determinantes do fluxo de capital e constroem um índice de controle de capital que abrange o período 1988-1995. Seguiremos o método utilizado por C\&G para calcularmos o índice de controle de capital, o qual denominaremos ICC. O primeiro indicador calculado foi o de variação em relação à legislação de entrada de capital, definido como $\Delta$ RI. Uma mudança na legislação relacionada à entrada de capital recebe o valor equivalente a -1 quando a norma é liberalizante, e o valor de +1 quando a norma é restritiva. $O$ segundo indicador foi o referente à legislação de saída de capital, $\Delta \mathrm{RO}$, que tem metodologia análoga, isto é, qualquer mudança restringindo a saída de capital recebe o sinal de +1 e mudanças liberalizando a saída -1 .

Entre janeiro de 1990 e dezembro de 2000, o DRI variou entre -4 e +6 , enquanto o $\Delta \mathrm{R} 0$ entre $-2 \mathrm{e}+4$. A média mensal do DRI foi de $-0,46$ e de $\Delta \mathrm{R} 0-0,15$, caracterizando uma tendência de liberação na entrada e na saída de capital. A Tabela 1 mostra a média mensal para diversos subperíodos da década de 1990. Esses subperíodos foram escolhidos com base nos principais eventos macroeconômicos e regimes de cambiais ocorridos: fase inicial do processo de liberalização do capital (janeiro/1990 a dezembro/1994), regime de bandas cambiais (janeiro/1995 a dezembro/1998) e regime de câmbio flexível (janeiro/1999 a junho/2000).

TABELA 1 - VARIAÇÃO DA LEGISLAÇÃO REFERENTE À ENTRADA E SAÍDA DE CAPITAL

\begin{tabular}{lcc}
\hline Período & $\Delta \mathrm{RI}$ & $\Delta \mathrm{R} 0$ \\
\hline Janeiro/1990 a junho/2000 & $-0,4621$ & $-0,1515$ \\
Janeiro/1990 a dezembro/1994 & $-0,2667$ & $-0,15$ \\
Janeiro/1995 a dezembro/1998 & $-0,5417$ & $-0,125$ \\
Janeiro/1999 a dezembro/2000 & $-0,7916$ & $-0,2083$ \\
\hline
\end{tabular}


A Tabela 1 mostra que entre janeiro de 1990 e dezembro de 1994 a média mensal do $\Delta \mathrm{RI}$ foi de $-0,27$, enquanto do $\Delta \mathrm{RO}$ foi de $-0,15$. Portanto, os quatro primeiros anos da década de 1990 foram caracterizados pelo incentivo à entrada de capital. Como exemplos, temos a aprovação do Anexo IV por meio da Resolução n ${ }^{\circ} 1.832 / 91$, a Resolução $n^{\circ}$ 1894/92, que reduziu o prazo de permanência no País dos investimentos estrangeiros, e a Circular $n^{\circ} 2.388 / 93$, que regulamentou a constituição e o funcionamento dos Fundos de Renda Fixa - Capital Estrangeiro. A aprovação do Anexo IV facilitou o ingresso de investidores institucionais estrangeiros, tais como fundos de pensão, companhias de seguros e fundos de investimento estrangeiro. Além disso, permitiram-se aplicações em valores mobiliários e investimentos em fundos de aplicação financeira, sem tributar os rendimentos e os ganhos de capital obtidos. Foi o instrumento mais utilizado para a entrada no mercado de ações e derivativos no Brasil.

Já no período que vai de janeiro de 1995 até 1998, a média mensal do $\Delta \mathrm{RI}$ foi de $-0,54$, enquanto a do $\Delta \mathrm{RO}$ foi de $-0,125$. Esse período foi caracterizado por três crises financeiras internacionais: mexicana, asiática e a russa. Essas crises causaram grande instabilidade no fluxo de capitais. O Banco Central respondeu com medidas cada vez mais liberalizantes para entrada de capital. Houve, porém, picos nesse período, em que houve medidas restritivas, principalmente entre outubro/94 e março/95, período imediatamente pós-Plano Real. Nessa época houve uma entrada maciça de capital, levando a autoridade monetária a editar normas restritivas ${ }^{10}$ para evitar que o câmbio continuasse a apreciar.

Por fim, a média do $\Delta$ RI de janeiro de 1999 a dezembro de 2000 foi de $-0,79$, enquanto do $\Delta \mathrm{RO}$ foi de $-0,21$. O período teve como marco a alteração do regime cambial, que passou de um sistema de bandas para um regime de câmbio flexível, e se caracterizou por ter uma legislação extremamente liberalizante na entrada de capital.

Os indicadores $\Delta \mathrm{RI}$ e $\Delta \mathrm{RO}$ podem ser combinados para formar um único índice. No entanto, segundo $C \& G$, as medidas relacionadas à saída de capital $(\Delta R O)$ podem ter dois efeitos opostos sobre o fluxo líquido de capitais. Em um primeiro momento a restrição à saída de capital leva à manutenção do fluxo. Porém, uma medida de cunho restritivo pode também levar os investidores a perceberem que tais restrições futuramente serão uma ameaça à remessa de seus retornos ao exterior. Dessa forma pode haver uma redução do fluxo de capital.

10 Destacaremos duas medidas restritivas de grande impacto: Resolução no 2147 , de 10.03.95, que revogou a permissão de pagamento antecipado de empréstimos em moeda e financiamentos à importação; Portaria do $\mathrm{MF} \mathrm{n}^{\mathrm{O}} 202$, de 10.08.1995, que aumentou IOF sobre captação de recursos estrangeiros. 
C\&G sugerem duas medidas de controles de capital. Na primeira medida, $\Delta \mathrm{CCl}$, o indicador referente à legislação de saída de capitais, $\Delta \mathrm{R} 0$, compõe o índice com sinal negativo, e peso $0,5,{ }^{11}$ como na equação a seguir:

$$
\Delta \mathrm{CC} 1=\Delta \mathrm{RI}-0,5 \Delta \mathrm{R} 0
$$

$\mathrm{Na}$ segunda medida, $\Delta \mathrm{CC} 2, \Delta \mathrm{R} 0$ é somado ao indicador $\Delta \mathrm{RI}$ com peso 0,5 , como na equação a seguir:

$$
\Delta \mathrm{CC} 2=\Delta \mathrm{RI}+0,5 \Delta \mathrm{R} 0
$$

O Gráfico 2 mostra os resultados do cálculo do $\Delta \mathrm{CCl}$ e $\Delta \mathrm{CC} 2$ no período 1990-2000. Os dois indicadores se comportam de forma bastante semelhante. Observamos que de janeiro/1990 a junho/1994 a maioria das medidas foi liberalizante, embora existam picos que revelam a ocorrência de medidas restritivas, principalmente em outubro/93 e março/94. Por outro lado, o período entre janeiro/95 e dezembro/96 foi misto, no sentido de ter havido tanto medidas liberalizantes quanto restritivas. A partir de 1997, especificamente julho de 1997, essa trajetória se inverteu e o Banco Central editou, majoritariamente, medidas de cunho liberalizante. Por meio do Gráfico 3, confirmase que houve uma abertura gradual e crescente da conta capital nos anos 1990. Essa tendência à liberalização da conta de capital ocorreu a partir da crise asiática de 1997, quando há um declive acentuado da curva. Entre 1997 até 2000, cerca de $90 \%$ das medidas foram de incentivo ou manutenção de capital.

GRÁFICO 2 - INDICES DE CONTROLE DE CAPITAL - VARIAÇÃO MENSAL

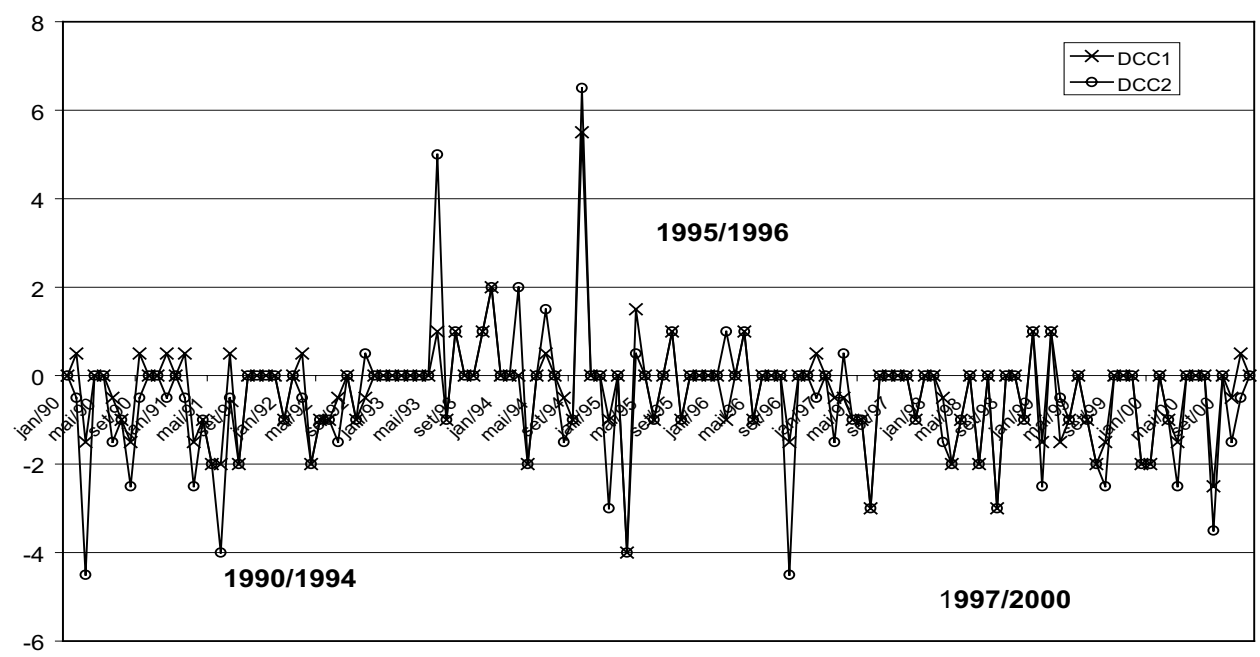

Fonte: Elaboração própria baseada na legislação do Bacen e do Ministério da Fazenda.

11 Por conta do efeito duvidoso que uma legislação restritiva de saída de capital pode ter sobre o fluxo, adotou-se o critério de ponderar pela metade o R0, o mesmo peso atribuído por C\&G. 
GRÁFICO 3 - INDICE DE CONTROLE DE CAPITAIS ACUMULADO

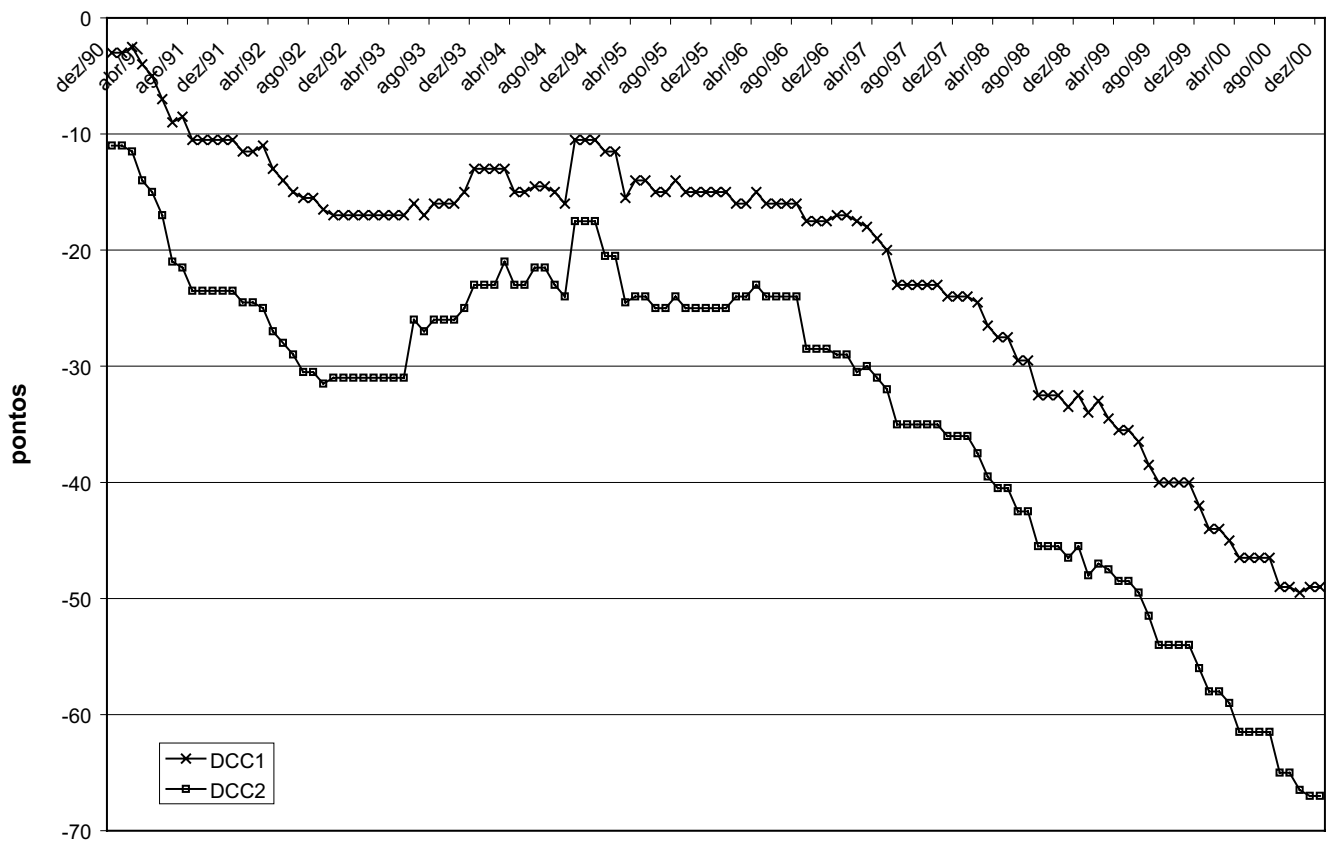

Fonte: Elaboração própria baseada na legislação do Bacen e do Ministério da Fazenda.

\subsection{Modelo Econométrico para Fluxo de Capital}

Seguindo Cardoso e Goldfajn (1997), o nosso modelo econométrico investiga o efeito da legislação de controles de capital sobre os fluxos de capital no Brasil, controlando para variáveis que representam os fatores pull e push. Em primeiro lugar reproduzimos o modelo utilizado por $C \& G$, com algumas modificaçóes, e em seguida reestimamos o modelo com uma nova especificação das variáveis. Finalmente, testamos a importância relativa da variável de legislação na explicação dos fluxos de capitais.

\subsubsection{Reproduzindo $C \& G$}

Começamos reproduzindo a primeira especificação de estimação de fluxo de capital de C\&G, com as seguintes modificaçóes. Em primeiro lugar, o período de tempo analisado é diferente. C\&G estudam o período de 1988 a 1995, enquanto que a nossa análise abrange o período de abril de 1990 a dezembro de 2000. Em segundo lugar, C\&G utilizam como variáveis pull e push a taxa de juros internacional e a taxa de juros doméstica descontada pela desvalorização cambial embutida no mercado futuro. Optamos por combinar essas duas medidas, calculando desvios da paridade coberta de 
juros (PJC). Este conceito incorpora, além da taxa de retorno esperada, o desconto da taxa de juros externa do Tesouro americano. Assim, um único indicador PJC substitui dois, a taxa $d$ retorno $\left(i-f_{d}\right)$ e a taxa internacional $\left(i^{*}\right)$. Este indicador nos parece mais completo, pois a teoria da paridade de juros sintetiza as inter-relaçóes entre taxa de juros e taxas de câmbio. Por fim, como nossa análise abrange um período de tempo mais amplo, no qual então incluímos variáveis dummies para captar o efeito contágio das crises cambiais ocorridas bem como o efeito do Plano Real.

Estimamos, portanto, a equação:

$$
\mathrm{FKL}_{\mathrm{t}}=\beta_{0}+\beta_{1} \mathrm{PJC}_{\mathrm{t}}+\beta_{2} \mathrm{LEG}_{\mathrm{t}}+\beta_{3} \text { Dcrises }_{\mathrm{t}}+\beta_{4} \text { Dreal }_{\mathrm{t}}+\varepsilon_{\mathrm{t}}
$$

em que FKL é o fluxo de capital líquido como proporção do PIB, PJC ${ }^{12}$ representa os desvios da paridade coberta de juros, ${ }^{13}$ LEG é a variável referente à legislação de controles de capital, que pode assumir os valores referentes à entrada de capital $(\Delta \mathrm{RI})$, à saída de capital $(\triangle \mathrm{RO})$, ou a combinação linear dos normativos referentes à entrada e saída de capital ( $\triangle \mathrm{CCl}$ e $\Delta \mathrm{CC} 2$ ). Dcrises é um vetor de dummies que captam os efeitos das crises internacionais: mexicana (janeiro a março de 1995), asiática (outubro a dezembro de 1997) e russa (julho a dezembro de 1998). Dreal representa a variável dummy para o Plano Real. O fluxo de capital líquido (FKL) foi classificado como o total de fluxo de capital, conforme definição do Banco Central, excluindo os outros capitais (garantias, obrigações com autoridade monetária e operações de regularização com o FMI), as operaçôes de refinanciamento e os capitais de curto prazo. O objetivo foi verificar o fluxo de capitais autônomos que entram no País, independentemente de operações governamentais, e retirar os ruídos causados pelo capital de curto prazo. Cabe ressaltar que nessa estimação procuramos reproduzir o modelo de $C \& G$, no qual também não é considerado o fluxo de curto prazo.

A Tabela 2 apresenta os resultados da estimação da equação (3). Os coeficientes das dummies México, Ásia e Rússia têm sinal negativo, embora o da Rússia não seja significativamente diferente de zero. Portanto, as crises internacionais tiveram um impacto negativo sobre os fluxos de capital para o Brasil. Quanto às variáveis relativas à legislação, apenas o índice $\Delta \mathrm{RI}$ teve coeficiente significativamente diferente de zero. O coeficiente da variável de desvios da paridade de juros, PJC, não foi sig-

12 Os desvios da paridade coberta de juros foram calculados usando a taxa do Fed Fund do Tesouro americano como proxy para a taxa de juros internacional, a taxa Selic como a taxa de juros doméstica e câmbio futuro no mercado de câmbio da BM\&F do $1^{\circ}$ dia útil.

13 Optamos por utilizar a paridade coberta da taxa de juros em vez da descoberta devido à falta de dados, já que não há disponibilidade de dados sobre expectativa de desvalorização cambial para a moeda brasileira na década de 1990. Poderíamos, como encontrado na literatura empírica, utilizar a desvalorização cambial efetivamente ocorrida como proxy para a sua expectativa, já que estas são formadas racionalmente. Consideramos, no entanto, que esta não seria uma boa proxy para a economia brasileira no período estudado. É razoável supor que as expectativas de desvalorização cambial na década de 1990 fossem enviesadas devido a expectativas de mudança de regime, gerando o conhecido "peso problem". Ver, por exemplo, Kaminsky (1993). 
nificativamente diferente de zero em nenhuma das 4 especificações apresentadas na Tabela 2. No trabalho de C\&G, quando se testou o período 1988 a 1995, todas as variáveis tiveram coeficientes estimados significativos, à exceção de $\Delta \mathrm{RO}$. No nosso teste, quando abrangemos o período mais amplo, nenhuma variável foi significativa, à exceção das dummies Real, México e Ásia. Portanto, os resultados obtidos por C\&G não resistem ao aumento do período estudado. A seguir, acrescentamos mais algumas modificações na estimação do modelo para os fluxos de capitais.

\section{TABELA 2 - VARIÁVEL DEPENDENTE: FLUXO DE CAPITAL DE MÉDIO E LONGO PRAZO COMO PROPORÇÃO DO PIB - PERÍODO ABRIL 1990 - DEZEMBRO DE 2000}

\begin{tabular}{|c|c|c|c|c|}
\hline & (1) & (2) & (3) & (4) \\
\hline Constante & $\begin{array}{c}1,01 \\
(2,80)\end{array}$ & $\begin{array}{c}0,82 \\
(2,02)\end{array}$ & $\begin{array}{c}0,87 \\
(2,18)\end{array}$ & $\begin{array}{c}0,77 \\
(1,93)\end{array}$ \\
\hline$\Delta \mathrm{RI}$ & $\begin{array}{c}0,55 \\
(1,64)\end{array}$ & - & - & - \\
\hline$\Delta \mathrm{RO}$ & - & $\begin{array}{c}-0,14 \\
(-0,50)\end{array}$ & - & - \\
\hline$\Delta \mathrm{CC} 1$ & - & - & - & $\begin{array}{c}-0,29 \\
(-0,96)\end{array}$ \\
\hline$\Delta \mathrm{CC} 2$ & - & - & $\begin{array}{c}-0,02 \\
(-0,10)\end{array}$ & - \\
\hline PJC & $\begin{array}{c}-0,02 \\
(-0,15)\end{array}$ & $\begin{array}{c}0,04 \\
(0,21)\end{array}$ & $\begin{array}{c}0,03 \\
(0,16)\end{array}$ & $\begin{array}{c}0,04 \\
(0,23)\end{array}$ \\
\hline Dummy Real & $\begin{array}{c}4,15 \\
(6,91)\end{array}$ & $\begin{array}{c}4,09 \\
(6,91)\end{array}$ & $\begin{array}{c}4,11 \\
(6,93)\end{array}$ & $\begin{array}{c}4,08 \\
(6,89)\end{array}$ \\
\hline Dummy México & $\begin{array}{c}-7,51 \\
(-5,05)\end{array}$ & $\begin{array}{c}-8,03 \\
(-5,14)\end{array}$ & $\begin{array}{c}-7,86 \\
(-5,32)\end{array}$ & $\begin{array}{c}-8,20 \\
(-4,87)\end{array}$ \\
\hline Dummy Ásia & $\begin{array}{c}-3,33 \\
(-1,96)\end{array}$ & $\begin{array}{c}-3,27 \\
(-1,89)\end{array}$ & $\begin{array}{c}-3,25 \\
(-1,89)\end{array}$ & $\begin{array}{c}-3,33 \\
(-1,90)\end{array}$ \\
\hline $\mathrm{R}^{2}$ ajustado & 0,24 & 0,23 & 0,23 & 0,24 \\
\hline
\end{tabular}

\subsection{Modelo Modificado}

Uma inovação em relação à estimação de C\&G será a abertura maior do fluxo de capital. Faremos as estimaçóes utilizando três conceitos de fluxos. O primeiro é a estimação baseada nos fluxos de médio e longo prazos, que corresponde aos investimentos, financiamentos e os empréstimos de médio e longo prazos. O segundo é o fluxo de curto prazo, ou seja, operações com prazo menor que 360 dias. Por fim, o chamado fluxo total, que é a soma das operações relacionadas com investimentos, financiamentos e empréstimos de médio e longo prazo e capital de curto prazo. ${ }^{14}$

14 A descrição das variáveis utilizadas na estimação encontra-se no Apêndice. 
A opção por utilizar três definições de fluxo foi verificar se o modelo é apropriado para explicar os diversos tipos de fluxos de capital. Há uma distinção básica entre fluxo de médio e longo prazos e fluxo de curto prazo. Os fluxos de capital de curto prazo são mais voláteis e transitórios e, por isso, devem ser mais sensíveis às mudanças nas taxas de juros de curto prazo e riscos de crédito. Já os fluxos de médio e longo prazos, dado o seu caráter de permanência, devem ser menos sensíveis às variaçóes de curtíssimo prazo, como mudança de juros. Por outro lado, estão mais expostos a riscos de longo prazo, como o risco soberano e o risco político. Acreditamos, assim, que por meio dessas três definiçôes de fluxos será possível gerar resultados mais robustos.

Os fluxos de capitais foram também acumulados em 12 meses. O fluxo de capital é uma variável muito sensível a alterações na economia doméstica e internacional, como taxas juros, política ou mesmo do humor dos investidores. Utilizando a variável acumulada evitam-se problemas, como a sazonalidade e ruídos causados por eventos momentâneos.

Os índices de legislação de controle de capital calculados captam as variações na legislação a cada período. No entanto, é razoável supor que o efeito da legislação seja cumulativo, isto é, uma nova legislação deve afetar não apenas o fluxo de capital no período vigente, mas também nos períodos subseqüentes. Portanto, utilizamos no novo modelo os índices de controle de capital acumulados em 12 meses.

Além disso, a variável de controle de capital foi defasada em um período. A defasagem é utilizada por dois motivos. Em primeiro lugar, o impacto da legislação sobre os fluxos pode ter uma defasagem. Em segundo lugar, a defasagem atenua o problema da endogeneidade, isto é, a possibilidade da legislação ser influenciada pelo próprio fluxo de capital. Acrescentamos, ainda, duas dummies de inclinação para medir possíveis efeitos diferenciados da legislação no tempo: segmentamos o período 1995-98 (regime de banda cambial) e 1999-2000 (regime de câmbio flexível). Além dessas mudanças, resolvemos não estimar o modelo utilizando os indicadores $\Delta \mathrm{CCl}$ e $\Delta \mathrm{CC} 2$, a fim de evitar a arbitrariedade do peso de 0,5 para $\Delta \mathrm{RO}$ para a construção de $\Delta \mathrm{CCl}$ e $\Delta \mathrm{CC} 2$.

As variáveis dummies para crises e para o Plano Real foram também acumuladas em 12 meses. Acreditamos que assim podemos captar o efeito do phasing-in e phasing-out das crises e do Plano Real.

A Tabela 3 apresenta os resultados da estimação que utiliza o índice acumulado de entrada de capital ( $\Delta$ RI acum) como variável de legislação. Nas colunas (1) e (2) usamos o fluxo de capitais de médio e longo prazos como variável dependente. $\mathrm{Na}$ coluna (1), os coeficientes da variável PJC e das dummies das crises internacionais do México e Rússia e a dummy Real foram significativos e com o sinal esperado. Quanto às variáveis dummies de inclinação, que testam o impacto diferenciado da legislação de entrada de capital no período 1995 a 1998 e 1999 a 2000, seu coeficiente é negativo, 
ou seja, uma legislação mais restritiva levava a um menor fluxo de capital no período. Já no período 1990 a 1994, o sinal do coeficiente de $\Delta \mathrm{RI} \operatorname{acum}_{(-1)}$ foi contrário ao período 1995-2000, mostrando que quanto mais restritiva a legislação de entrada de capital em 1990-1994, maior o fluxo de capital.

As colunas (3) e (4) apresentam os resultados para a estimação usando o fluxo de curto prazo como variável dependente. O resultado da coluna (4) mostra que os coeficientes da variável PJC e das dummies das crises internacionais da Ásia e da Rússia foram significativos e com o sinal esperado. Quanto ao Plano Real, este não teve impacto significativo, e o coeficiente da dummy relacionada ao México, embora significativo, não foi de acordo com o sinal esperado. Também neste teste de curto prazo nenhuma variável relacionada à legislação foi significativa.

TABELA 3 - VARIÁVEL DEPENDENTE: FLUXO DE CAPITAL COMO PROPORÇÃO DO PIB, ACUMULADOS EM 12 MESES (PERÍODO: JAN. 1991-DEZ. 2000)

\begin{tabular}{|c|c|c|c|c|c|c|}
\hline \multirow{3}{*}{ Variável Explicativa } & \multicolumn{6}{|c|}{ Variável Dependente } \\
\hline & \multicolumn{2}{|c|}{$\begin{array}{l}\text { Fluxo de Capitais de Médio } \\
\text { e Longo Prazo / PIB }\end{array}$} & \multicolumn{2}{|c|}{$\begin{array}{c}\text { Fluxo de Capitais de Curto } \\
\text { Prazo / PIB }\end{array}$} & \multicolumn{2}{|c|}{ Fluxo de Capitais Total/ PIB } \\
\hline & (1) & (2) & (3) & (4) & (5) & (6) \\
\hline Constante & $\begin{array}{c}0,73 \\
(4,28)\end{array}$ & $\begin{array}{c}0,88 \\
(5,61)\end{array}$ & $\begin{array}{c}-0,27 \\
(-0,99)\end{array}$ & $\begin{array}{c}-0,36 \\
(-1,31)\end{array}$ & $\begin{array}{c}0,46 \\
(1,25)\end{array}$ & $\begin{array}{c}0,52 \\
(1,37)\end{array}$ \\
\hline PJC & $\begin{array}{c}0,03 \\
(6,95)\end{array}$ & $\begin{array}{c}0,03 \\
(6,32)\end{array}$ & $\begin{array}{c}0,04 \\
(3,78)\end{array}$ & $\begin{array}{c}0,04 \\
(3,70)\end{array}$ & $\begin{array}{c}0,07 \\
(5,67)\end{array}$ & $\begin{array}{c}0,07 \\
(5,33)\end{array}$ \\
\hline$\Delta \mathrm{RI} \operatorname{acum}_{(-1)}$ & $\begin{array}{c}0,07 \\
(4,44)\end{array}$ & $\begin{array}{c}0,12 \\
(7,25)\end{array}$ & $\begin{array}{c}0,01 \\
(0,37)\end{array}$ & $\begin{array}{c}0 \\
(0)\end{array}$ & $\begin{array}{c}0,08 \\
(2,73)\end{array}$ & $\begin{array}{c}0,12 \\
(3,76)\end{array}$ \\
\hline D9598 RI $\operatorname{acum}_{(-1)}$ & - & $\begin{array}{c}-0,39 \\
(-7,57)\end{array}$ & - & $\begin{array}{c}0,01 \\
(0,07)\end{array}$ & - & $\begin{array}{c}-0,38 \\
(-4,47)\end{array}$ \\
\hline D9900 RI $\operatorname{acum}_{(-1)}$ & - & $\begin{array}{c}-0,19 \\
(-2,66)\end{array}$ & - & $\begin{array}{c}0,10 \\
(1,29)\end{array}$ & - & $\begin{array}{c}-0,09 \\
(-0,83)\end{array}$ \\
\hline Dummy Real acum & $\begin{array}{c}0,07 \\
(27,06)\end{array}$ & $\begin{array}{c}0,05 \\
(4,76)\end{array}$ & $\begin{array}{c}-0,02 \\
(-7,48)\end{array}$ & $\begin{array}{c}-0,01 \\
(-0,79)\end{array}$ & $\begin{array}{c}0,05 \\
(12,47)\end{array}$ & $\begin{array}{c}0,04 \\
(2,47)\end{array}$ \\
\hline Dummy México acum & $\begin{array}{c}-0,59 \\
(-8,83)\end{array}$ & $\begin{array}{c}-0,70 \\
(-8,89)\end{array}$ & $\begin{array}{c}0,24 \\
(2,18)\end{array}$ & $\begin{array}{c}0,22 \\
(2,07)\end{array}$ & $\begin{array}{l}-0,35 \\
(-2,09)\end{array}$ & $\begin{array}{l}-0,48 \\
(-3,55)\end{array}$ \\
\hline Dummy Ásia acum & $\begin{array}{c}1,02 \\
(8,60)\end{array}$ & $\begin{array}{c}0,38 \\
(2,66)\end{array}$ & $\begin{array}{c}-0,50 \\
(-9,57)\end{array}$ & $\begin{array}{c}-0,68 \\
(-6,14)\end{array}$ & $\begin{array}{c}0,52 \\
(3,94)\end{array}$ & $\begin{array}{c}-0,30 \\
(-1,75)\end{array}$ \\
\hline Dummy Rússia acum & $\begin{array}{c}-0,19 \\
(-1,74)\end{array}$ & $\begin{array}{c}-0,26 \\
(-3,97)\end{array}$ & $\begin{array}{c}-0,63 \\
(-17,62)\end{array}$ & $\begin{array}{c}-0,64 \\
(-17,55)\end{array}$ & $\begin{array}{l}-0,82 \\
(-6,42)\end{array}$ & $\begin{array}{c}-0,90 \\
(-11,65)\end{array}$ \\
\hline $\mathrm{R}^{2}$ & 0,85 & 0,92 & 0,83 & 0,84 & 0,67 & 0,78 \\
\hline $\mathrm{R}^{2}$ - ajustado & 0,85 & 0,92 & 0,82 & 0,82 & 0,65 & 0,76 \\
\hline
\end{tabular}


Quanto ao fluxo total, os coeficientes das variáveis dummy Real e as dummies das crises do México, Ásia e Rússia foram significativos e com o sinal esperado. A PJC foi significativa e positiva, mostrando que quanto maior a taxa de retorno medida pelo desvio da paridade de juros, maior foi o fluxo total. O Plano Real teve um impacto positivo sobre os fluxos de capital, enquanto que as crises internacionais foram negativamente correlacionadas ao fluxo de capital. Quanto à legislação, o coeficiente da variável dummy de inclinação, que testa o impacto da legislação de entrada de capital no período 1995 a 1998, mostra que quanto mais restritiva a legislação de entrada de capital, menor foi o fluxo de capital.

Um resultado aparentemente contra-intuitivo foi o da crise asiática, que aparece como positivamente correlacionado com o fluxo de médio e longo prazo. No entanto, este resultado pode ser interpretado da seguinte forma. Os investidores deixaram a Ásia e passaram a investir na América Latina, principalmente a partir de 1997, aproveitando, por exemplo, o processo de privatização. O Brasil pode ter se tornado um país relativamente mais atrativo para os investidores internacionais.

A Tabela 4 apresenta os resultados da estimação que utiliza o índice acumulado de controle de saída de capital ( $\Delta$ ROacum) como variável de legislação. As colunas (1) e (2) apresentam os resultados da estimação para o fluxo de capitais de médio e longo prazos como variável dependente. Os resultados encontrados foram análogos àqueles referentes à legislação de controle de entrada de capital, apresentados na Tabela 3.

Quando se testaram as variáveis acumuladas em 12 meses, obtivemos os resultados mais robustos, conforme demonstrado nas Tabelas 3 e 4 , tanto pelo $\mathrm{R}^{2}$ e $\mathrm{R}^{2}$ ajustado quanto pelo número de variáveis significativas e com os sinais esperados.

As variáveis relativas à legislação, tanto de entrada $(\Delta \mathrm{RI})$ como saída de capital $(\Delta \mathrm{RO})$, têm impacto significativo sobre os fluxos de capitais de médio e longo prazos, porém não nos de curto prazo. Nos testes de fluxo total e de fluxo de médio e longo prazos, a legislação de entrada e saída de capital para o período de 1995 a 1998 foi significativa e negativamente relacionada ao fluxo, como esperado. Já no período 1999 a 2000, a legislação de entrada de capital só foi significativa no fluxo de médio e longo prazos, enquanto a legislação de saída de capital não foi significativa em nenhum fluxo. Finalmente, para o período 1990 a 1994, os sinais de $\Delta \mathrm{RI}$ e $\Delta \mathrm{RO}$ foram positivamente correlacionados ao fluxo, sugerindo que a legislação restritiva aumentou o fluxo nesse período. 
TABELA 4 - VARIÁVEL DEPENDENTE: FLUXO DE CAPITAL COMO PROPORÇÃO DO PIB, ACUMULADOS EM 12 MESES (PERÍODO: JAN. 1991-DEZ. 2000)

\begin{tabular}{|c|c|c|c|c|c|c|}
\hline \multirow{3}{*}{ Variável Explicativa } & \multicolumn{6}{|c|}{ Variável Dependente } \\
\hline & \multicolumn{2}{|c|}{$\begin{array}{l}\text { Fluxo de Capitais de Médio } \\
\text { e Longo Prazo / PIB }\end{array}$} & \multicolumn{2}{|c|}{$\begin{array}{c}\text { Fluxo de Capitais de Curto } \\
\text { Prazo / PIB }\end{array}$} & \multicolumn{2}{|c|}{ Fluxo de Capitais Total/ PIB } \\
\hline & (1) & (2) & (3) & (4) & (5) & (6) \\
\hline Constante & $\begin{array}{c}0,97 \\
(5,41)\end{array}$ & $\begin{array}{c}1,18 \\
(5,98)\end{array}$ & $\begin{array}{c}-0,30 \\
(-1,02)\end{array}$ & $\begin{array}{c}-0,33 \\
(-1,13)\end{array}$ & $\begin{array}{c}0,67 \\
(1,69)\end{array}$ & $\begin{array}{c}0,86 \\
(2,02)\end{array}$ \\
\hline PJC & $\begin{array}{c}0,02 \\
(2,57)\end{array}$ & $\begin{array}{c}0,01 \\
(1,12)\end{array}$ & $\begin{array}{c}0,04 \\
(3,16)\end{array}$ & $\begin{array}{c}0,04 \\
(3,19)\end{array}$ & $\begin{array}{c}0,06 \\
(3,61)\end{array}$ & $\begin{array}{c}0,05 \\
(2,82)\end{array}$ \\
\hline$\Delta \mathrm{RO} \operatorname{acum}_{(-1)}$ & $\begin{array}{c}0,14 \\
(5,02)\end{array}$ & $\begin{array}{c}0,21 \\
(7,79)\end{array}$ & $\begin{array}{c}0,01 \\
(0,16)\end{array}$ & $\begin{array}{c}-0,01 \\
(-0,24)\end{array}$ & $\begin{array}{c}0,14 \\
(3,10)\end{array}$ & $\begin{array}{c}0,21 \\
(4,10)\end{array}$ \\
\hline D9598 RO $\operatorname{acum}_{(-1)}$ & - & $\begin{array}{c}-0,47 \\
(-7,26)\end{array}$ & - & $\begin{array}{c}0,08 \\
(1,16)\end{array}$ & - & $\begin{array}{c}-0,39 \\
(-3,86)\end{array}$ \\
\hline D9900 RO $\operatorname{acum}_{(-1)}$ & - & $\begin{array}{c}-0,14 \\
(-0,70)\end{array}$ & - & $\begin{array}{c}0,07 \\
(0,52)\end{array}$ & - & $\begin{array}{c}-0,06 \\
(-0,25)\end{array}$ \\
\hline Dummy Real acum & $\begin{array}{c}0,07 \\
(28,90)\end{array}$ & $\begin{array}{c}0,06 \\
(11,44)\end{array}$ & $\begin{array}{c}-0,02 \\
(-10,24)\end{array}$ & $\begin{array}{l}-0,02 \\
(-4,36)\end{array}$ & $\begin{array}{r}0,05 \\
(14,29)\end{array}$ & $\begin{array}{l}0,04 \\
(6,18)\end{array}$ \\
\hline Dummy México acum & $\begin{array}{c}-0,41 \\
(-5,39)\end{array}$ & $\begin{array}{c}-0,61 \\
(-10,11)\end{array}$ & $\begin{array}{c}0,24 \\
(2,11)\end{array}$ & $\begin{array}{c}0,28 \\
(2,30)\end{array}$ & $\begin{array}{c}-0,16 \\
(-0,94)\end{array}$ & $\begin{array}{c}-0,33 \\
(-2,30)\end{array}$ \\
\hline Dummy Ásia acum & $\begin{array}{c}0,93 \\
(7,86)\end{array}$ & $\begin{array}{c}0,89 \\
(6,92)\end{array}$ & $\begin{array}{c}-0,51 \\
(-9,17)\end{array}$ & $\begin{array}{c}-0,52 \\
(-7,20)\end{array}$ & $\begin{array}{c}0,42 \\
(3,13)\end{array}$ & $\begin{array}{c}0,37 \\
(2,45)\end{array}$ \\
\hline Dummy Rússia acum & $\begin{array}{c}-0,21 \\
(-2,03)\end{array}$ & $\begin{array}{c}-0,18 \\
(-1,87)\end{array}$ & $\begin{array}{c}-0,63 \\
(-17,97)\end{array}$ & $\begin{array}{c}-0,64 \\
(-14,81)\end{array}$ & $\begin{array}{c}-0,84 \\
(-6,83)\end{array}$ & $\begin{array}{c}-0,82 \\
(-7,09)\end{array}$ \\
\hline $\mathrm{R}^{2}$ & 0,86 & 0,91 & 0,83 & 0,83 & 0,67 & 0,71 \\
\hline $\mathrm{R}^{2}$ - ajustado & 0,85 & 0,90 & 0,82 & 0,82 & 0,66 & 0,69 \\
\hline
\end{tabular}

\subsection{A Importância da Variável Legislação}

Para testarmos a importância da legislação na determinação fluxo de capital faremos um teste comparando o modelo completo, conforme definido na equação (3), e o modelo reduzido, retirando as variáveis relacionadas à legislação, conforme definido na equação (4).

FKLacum $_{\mathrm{t}}=\beta 0_{\mathrm{t}}+\beta 1$ PJCacum $_{\mathrm{t}}+\beta 2$ DRealacum $_{\mathrm{t}}+\beta 3$ Dcrisesacum $_{\mathrm{t}}+\varepsilon_{\mathrm{t}}$ 
TABELA 5 - MODELO REDUZIDO E MODELO COMPLETO

\begin{tabular}{lccc}
\hline & Médio e Longo Prazos & Curto Prazo & Total \\
\hline $\mathrm{R}^{2}$ modelo completo & 0,9214 & 0,8364 & 0,7794 \\
$\mathrm{R}^{2}$ ajustado modelo completo & 0,9157 & 0,8264 & 0,7635 \\
$\mathrm{R}^{2}$ modelo reduzido & 0,8437 & 0,8267 & 0,6505 \\
$\mathrm{R}^{2}$ ajustado modelo reduzido & 0,8368 & 0,8191 & 0,6351 \\
\hline
\end{tabular}

$\mathrm{O} \mathrm{R}^{2}$ e o $\mathrm{R}^{2}$ ajustado do modelo completo referem-se à Tabela 3.

A Tabela 5 apresenta os resultados do $\mathrm{R}^{2}$ e o $\mathrm{R}^{2}$ ajustado do chamado modelo reduzido, ou seja, retirando as variáveis relacionadas à legislação. Como era de se esperar, a capacidade explicativa da regressão diminui com a retirada da variável de legislação. No entanto, esta diminuição é maior para os fluxos de médio e longo prazo, em que $\mathrm{R}^{2}$ e o $\mathrm{R}^{2}$ ajustado caem quase 10 pontos. Já para o fluxo de curto prazos, a capacidade explicativa da regressão não é muito alterada quando se retira a variável de legislação, confirmando as evidências anteriores de que a legislação não explica esse fluxo, que é mais afetado pelo efeito push e pelo contágio dado pelas crises internacionais. Nossos próximos testes visam investigar a contribuição de cada variável do modelo especificado pela equação (3). Para isso, utilizaremos o procedimento "stepwise", SAS versão 8.0 .

A Tabela 6 ordena, por ordem de importância, as variáveis do modelo utilizando o $\mathrm{R}^{2}$ parcial e empregando como variável legislação a restrição à entrada de capital. Apenas as variáveis cujo valor-p foi inferior ou igual a 0,05 foram selecionadas.

Conforme podemos observar, para o fluxo de médio e longo prazos, a variável mais significativa foi a dummy do Plano Real, cujo $\mathrm{R}^{2}$ parcial foi de 0,6551 , seguida da legislação de entrada de capital para o período 1995-1998, cujo $\mathrm{R}^{2}$ parcial foi de 0,1339. Ou seja, conforme visto na literatura, os fatores pull são os mais relevantes para explicar o fluxo no médio e longo prazo. Já no curto prazo, a variável mais significativa foi a crise russa, que apresentou $\mathrm{R}^{2}$ parcial de 0,5207 , seguida da crise asiática, $\mathrm{R}^{2}$ parcial de 0,133 . O efeito contágio provocado por essas crises afastou o capital, sendo determinante para explicar esse fluxo. Finalmente, no fluxo total confirmamos que os fatores pull, push e contágio explicam o fluxo de forma equilibrada. 
TABELA 6 - VARIÁVEL DEPENDENTE: FLUXO DE CAPITAL COMO PROPORÇÃO DO PIB(PERÍODO: JAN. 1991-DEZ. 2000) FLUXOS ACUMULADOS EM 12 MESES, TESTANDO R2 PARCIAL

\begin{tabular}{lclccc}
\hline $\begin{array}{l}\text { Variáveis } \\
\text { Explicativas }\end{array}$ & Médio\&LP & $\begin{array}{c}\text { Variáveis } \\
\text { Explicativas }\end{array}$ & Curto Prazo & $\begin{array}{c}\text { Variáveis } \\
\text { Explicativas }\end{array}$ & Total \\
\hline Dreal & 0,6551 & DRússia & 0,5207 & DRússia & 0,1999 \\
D9598RI $_{(-1)}$ & 0,1339 & DÁsia & 0,133 & DReal & 0,1809 \\
RRIAcum $_{(-1)}$ & 0,0435 & DReal & 0,0843 & PJC & 0,1751 \\
Dméxico & 0,0408 & PJC & 0,0775 & D9598RI & 0,1627 \\
Drússia & 0,0208 & DMéxico & 0,0113 & $\Delta$ RIacum $_{(-1)}$ & 0,0264 \\
PJC & 0,0134 & & & Dméxico & 0,0253 \\
Dásia & 0,0075 & & DÁsia & 0,0072 \\
D9900RI & 0,0064 & & & & \\
\hline
\end{tabular}

Nota: Testa-se a variável legislação relacionada à entrada de capital. Todas as variáveis estão acumuladas em 12 meses. O D é a abreviação de dummy.

\section{CONCLUSÃO}

O processo de liberalização da conta capital começou ao final dos anos 1980 e consolidou-se na década de 1990. As modificações introduzidas nas principais modalidades de investimento estrangeiro no mercado financeiro no Brasil buscaram adaptar e ampliar os meios disponíveis para aplicações de não-residentes, de forma a contemplar as transformações ocorridas no sistema financeiro internacional, vis-à-vis à economia brasileira. A base desse processo foi a retomada dos fluxos financeiros entre o País e o mercado internacional, bem como a estabilização da economia. Além disso, o Brasil, como outros países emergentes, se beneficiou dos fatores externos favoráveis, tais como a queda da taxa de juros internacional nos países industrializados. A combinação desses elementos deu impulso à inserção da economia brasileira nos principais canais de negociação de fluxos financeiros internacionais, além de promover expansão e sofisticação dos mercados de capitais locais.

No âmbito interno, além do Plano Real e das reformas econômicas, destacamos em nosso trabalho o papel da legislação relativa a controle de capital. A legislação sobre capitais externos do Banco Central do Brasil avançou, havendo uma clara tendência a liberalizar as operaçóes de mercado financeiro e de capitais. A implementação da Resolução no $1289 / 87$, na qual foram criados vários instrumentos de investimentos disponíveis aos não-residentes no Brasil e para os residentes investirem no exterior constituiu-se, sem dúvida, um marco. Essa resolução sofreu várias alterações ao longo da década, merecendo destaque a aprovação do Anexo IV, que facilitou o ingresso 
de investidores institucionais, tais como fundos de pensão, companhias de seguros e fundos de investimento estrangeiro. Além disso, permitiu aplicações em valores mobiliários em fundos de aplicação financeira, sem tributar os rendimentos e os ganhos de capital obtidos.

Analisamos os determinantes de fluxo de capital, incluindo a legislação de controle de capital como variável explicativa. Encontramos que, para o fluxo de médio e longo prazos, os efeitos pull (dummy Real e legislação de controle de capital), push (paridade de juros coberta) foram relevantes para explicar o fluxo, o mesmo acontecendo com o efeito contágio produzido pelas crises mexicana, russa e asiática. Um resultado interessante foi que a crise asiática teve um impacto positivo sobre os fluxos de capital para o Brasil.

Para o fluxo de capital de curto prazo, as variáveis explicativas relevantes foram os desvios da paridade coberta de juros (efeito push) e efeito contágio (crises asiáticas e russa). O efeito pull do Plano Real não foi relevante. Esta conclusão corrobora os estudos de Garcia e Valpassos (1998). Os autores enfatizam que para aplicações de curto prazo o efeito push prevalece sobre o efeito pull. Para os investimentos de curto prazo, o diferencial de juros foi um fator determinante para atração do capital, enquanto que o efeito contágio proveniente de crises externas afasta o capital. Portanto, quando há uma crise externa os investidores deixam de comprar títulos brasileiros. Para voltar a atrair o investidor de curto prazo é preciso que o diferencial de juros seja atrativo o suficiente para se sobrepor aos riscos de países emergentes como o Brasil.

Já para o fluxo total, as variáveis explicativas relevantes foram os efeitos pull, push e contágio, dados pelo Plano Real, legislação de controle de capital, paridade de juros coberta e crises externas. Nossos resultados corroboram as evidências encontradas, para países da América Latina, por Calvo et al. (1993) e Fernández-Arias e Montiel (1995), que mostram que os efeitos push, pull e contágio, ou seja, que os três fatores foram determinantes para explicar o fluxo de capitais.

\section{REFERÊNCIAS BIBLIOGRÁFICAS}

Banco Central do Brasil. Nota para imprensa. Diversos números, Brasília- DF.

Calvo, G. Capital inflows and macroeconomic management: tequila lessons. International Journal of Finance and Economics, v. 1, julho 1996.

Calvo, G.; Leiderman, L.; Reinhart, C. Capital inflows and real exchange rate appreciation in Latin America: the role of external factors. International Monetary Fund, Paper no 40, 1993. 
Cardoso, E.; Goldfajn, I. Capital flows to Brazil: the endogeneity of capital controls. International Monetary Fund, Paper n ${ }^{\circ}$ 115, 1997.

Edwards, S. Capital flows, real exchange rates, and capital controls: some Latin American experiences. NBER Working Paper 6800, 1998.

. Capital controls, sudden stops and current account reversals. NBER Working Paper 11170, 2005.

Eichengreen, Barry. Crises financeiras: análise, prevenção e gestão. Rio de Janeiro: Campus, 2003.

Fernández-Arias, E.; Montiel, J. P. The surge in capital inflows to developing countries: analytical overview. Policy Research, Working Paper 1473, Washington: World Bank, 1995.

Garcia, M. G. P.; Valpassos, M. V. F. Capital flows, capital controls and currency crisis: the case of Brazil in the nineties. Texto para Discussão no 345, PUC-Rio, 1998.

Goldfajn, I.; Minella, A. Capital flows and controls in Brazil: what have we learned? In: Sebastian Edwards (ed.), International capital flows. NBER, 2005.

IMF Research Bulletin, v. 2, n. 4, dezembro 2001.

Kaminsky, G. Is there a peso problem? American Economic Review, junho 1993.

Kaplan, E.; Rodrik, D. Did the Malaysian capital controls work? Harvard University, 2001. Mimeografado.

Lessar, D.; Williamson, J. Capital flight: the problem and policy responses. Institute for International Economics, no 23, novembro 1987.

Stiglitz, J. Globalization and its discontents. New York and London: W.W. Norton, 2002.

Valdes-Prieto, Salvador; Soto, Marcelo. Es el control selectivo de capitales efectivo en Chile? Su efecto sobre el tipo de cambio real. Cuadernos de Economia, 33, abril 1996.

APÊNDICE - DESCRIÇÃO DAS VARIÁVEIS UTILIZADAS NA ESTIMAÇÃO

Taxa de Juros Domésticas (i): Medida pela taxa mensal do Sistema Especial de Liquidação e de Custódia (SELIC) para títulos federais, no primeiro dia útil de cada mês.

Taxa de Juros Internacional $\left(i^{*}\right)$ : Medida pela taxa mensal de juros do Tesouro Americano (Fed Fund).

Fluxo de Capital Utilizado na Tabelas 3: Estatísticas mensais do Banco Central do Brasil baseada na tabela de movimento de capitais. O fluxo considerado foi o fluxo 
total excluindo o fluxo de curto prazo, refinanciamentos e demais capitais (garantias e operações de regularização).

Fluxo de Capital Utilizado nas Tabela 4 e 5: Estatísticas mensais do Banco Central do Brasil baseada na tabela de movimento de capitais. O fluxo total é o fluxo de operações de médio e longo prazos excluindo refinanciamento e demais capitais (garantias e operações de regularização). O fluxo de médio e longo prazos é o que consideramos fluxo total excluindo operações de curto prazo. O fluxo de curto prazo é o capital de curto prazo encontrado na conta capital do Banco Central do Brasil.

Índice de Controle de Capital de Cardoso e Goldfajn: Índice construído baseado na lista de medidas coletada para o período 1990-2000. Para os interessados em obter o índice, entrar em contato com soihet@fgv.br.

$\Delta \mathrm{RI}$ é o saldo mensal entre as legislaçóes liberalizantes e restritivas, na entrada de capital;

$\Delta R O$ é o saldo mensal entre as legislações liberalizantes e restritivas, na saída de capital. A partir dessas definições são construídos dois indicadores:

$\Delta \mathrm{CC} 1=\Delta \mathrm{RI}-0,5 \Delta \mathrm{RO}$ e $\Delta \mathrm{CC} 2=\Delta \mathrm{RI}+0,5 \Delta \mathrm{RO}$

Crises (México, Ásia, Rússia): Dummy tequila (janeiro, fevereiro e março de 1995); dummy asiática (outubro, novembro, dezembro de 1997) e dummy russa (julho, agosto, setembro, outubro, novembro, dezembro de 1998).

Taxa de Retorno ( $\mathbf{i}-f_{\mathrm{d}}$ ): Medida mensal baseada na taxa de juros Selic deflacionada pelo desconto futuro calculado por meio do câmbio futuro no $1^{\circ}$ dia encontrado no site da BM\&F.

Plano Real: Dummy real (a partir de agosto de 1994).

Paridade de Juros Coberta (PJC): Medida mensal da taxa de juros doméstica (taxa Selic) deflacionada pela taxa de juros internacional (taxa de juros do Fed Fund do Tesouro Americano) e pelo desconto futuro calculado por meio do câmbio futuro no $1^{\circ}$ dia útil encontrado no site da (BM\&F).

PIB Nominal Mensal: PIB encontrado na nota da imprensa setor fiscal do Banco Central do Brasil. 